\title{
Calf Pain as a Prominent Feature of Behçet's Disease
}

\author{
Grace G. Penserga, MD and Evelyn Osio-Salido, MD, MSc \\ Division of Rheumatology, Department of Medicine, Philippine General Hospital, University of the Philippines Manila
}

\begin{abstract}
Objective. This study aimed to present four cases of Behçet's disease (BD) wherein recurrent calf pain was the first and prominent symptom experienced by the patients.

Methodology. The case series described the clinical features, disease development, management, and outcomes of these patients. Written consent was obtained from each participant for the review and publication of their case.

Results. All cases presented with chronic and recurrent calf pain, three of whom were bilateral. All four had skin changes on the lower extremities that may have contributed to leg pain. Only probing was a history of oral ulcers reported in all four; none had genital ulcers, eye abnormality, or sensory or motor deficits. All presented with elevated acute phase reactants. Based on the 2013 International Criteria for Behçet's Disease (ICBD), a diagnosis of possible $\mathrm{BD}$ was made due to the presence of oral ulcers, skin lesions, and absence of other findings pointing to another connective tissue disease or systemic vasculitides. All four cases were given oral corticosteroids and colchicine, but two required the addition of methotrexate and azathioprine for control of symptoms.
\end{abstract}

Conclusion. A complaint of recurrent calf pain warrants inquiry and examination of the skin lesions over the affected area and other areas like the oral cavity and genital area. It also warrants consideration of a vasculitic process, especially in the background of oral ulcers and skin changes. In such cases, BD is the right differential diagnosis to be considered.

Key Words: Behçet's Disease, leg pain, 2013 ICBD Classification Criteria

\section{INTRODUCTION}

$\mathrm{BD}$ is a multisystem disorder caused primarily by systemic vasculitis affecting most vascularized organ systems. The most common clinical features include oral ulcers, genital ulcers, ocular and skin lesions, but joint, eye, and neurologic organ systems can also be affected. Skin involvement can manifest as erythema nodosum or pseudofolliculitis; the ocular disease can manifest as visual disturbance and blindness in one-fourth of patients; neurologic involvement ranges from headache syndromes to dural sinus thrombosis and aseptic meningitis, while articular manifestations vary from arthralgia to non-erosive, non-deforming oligoarthritic. ${ }^{1,2}$ Most often in leg pain, muscle disease is a rare manifestation of $\mathrm{BD}$ and has only been reported in a handful of cases. ${ }^{2}$ Significant morbidity or death can occur with severe pulmonary hemorrhage cases, CNS or cardiac involvement vasculitis. ${ }^{2-4}$

BD prevalence varies from $0.1 / 1,000$ and $1 / 10,000$,

Corresponding author: Grace G. Penserga, MD

Division of Rheumatology

Department of Medicine

Philippine General Hospital, University of the Philippines Manila

Taft Avenue, Manila 1000, Philippines

Email: ggpenserga@up.edu.ph but the highest number of cases are reported in Turkey and Japan. ${ }^{1,2}$ Though there are no epidemiological data available, $\mathrm{BD}$ is presumed to be even rarer in the Philippines, with only 31 cases documented in the Philippine General Hospital, the largest tertiary referral center. The most common symptoms 
were mouth ulcers, followed by ocular findings such as visual impairment and uveitis; skin lesions such as erythema nodosum, pustulosis, and folliculitis; genital ulcers; and vascular anomalies such as deep venous thrombosis, venous insufficiency, and anti-phospholipid antibody syndrome. The study concluded that there is an average delay of three years in the diagnosis of $\mathrm{BD}$, perhaps due in part to the rarity of $\mathrm{BD}$ in our country and our unfamiliarity with the disease. ${ }^{5}$

We present four BD cases wherein instead of the abovementioned usual symptomatology, recurrent calf pain was the first and most prominent symptom at presentation. The diagnosis of $\mathrm{BD}$ of these cases was based on the 2013 International Criteria for BD (ICBD). ${ }^{6}$ Written consent was obtained from the participants to review their medical records and publication of their case. The clinical features, disease development, management, and outcomes of these four cases were described in this case series to describe an uncommon presenting manifestation of an already locally uncommon disease.

\section{CASE PRESENTATION}

\section{Case 1}

A 37-year-old female consulted for leg pain of three years duration, aggravated by prolonged standing and walking. This was followed by the appearance of 2-3 erythematous nodules, $2 \mathrm{~cm}$ in diameter, on the left leg, which would disappear after three days and leave areas of hyperpigmentation. The pain was alleviated by leg elevation. New lesions would appear around 2-3 times a month. Later she had lesions in both legs, this time associated with multiple painful oral ulcers and occurring monthly. Her first consult showed an erythrocyte sedimentation rate (ESR) of $45 \mathrm{~mm} / \mathrm{hr}(0-22 \mathrm{~mm} / \mathrm{hr})$, C-reactive protein (CRP) of 24 $\mathrm{mg} / \mathrm{L}(1-3 \mathrm{mg} / \mathrm{L})$, and negative anti-nucleotide antibody immunofluorescence (ANA-IF). Doppler studies of the lower extremities showed adequate systolic velocities and no evidence of deep venous thrombosis nor venous insufficiency.

At the time of the consult at our center, she had no oral, nasal or genital ulcers. A review of systems showed no malar rashes, alopecia, history of epistaxis or chronic cough, joint pains, limb claudication, frothy urine, or hematuria. There was also no history of obstetric complications. There was no note of visual disturbances, uveitis, genital ulcers, or motor and sensory deficits. There were hyperpigmented patches on the lower extremities from mid-tibia to ankle and several erythematous, tender nodules. Punch biopsy of the skin lesion showed erythema nodosum with septal panniculitis. Complete blood count (CBC) showed hemoglobin of 114 $\mathrm{g} / \mathrm{L}$, platelet of $314 \times 10^{9} / \mathrm{L}$, white blood cell count of $10.5 \mathrm{x}$ $10 \%$, and normal differential counts. Pro-time, fasting blood sugar, creatinine, aminotransferase enzymes, and urinalysis was all normal. Pathergy test was negative. Repeat ESR was $85 \mathrm{~mm} /$ hour. A preliminary consideration of BD was made. She was started on colchicine and prednisone.
On follow-up after a month of treatment, there was no recurrence of oral ulcers. The nodules on the lower extremities decreased in number and eventually resolved. Ophthalmology screening was regular. Repeat ESR was $54 \mathrm{~mm} / \mathrm{hr}$. Prednisone was tapered off after three months.

\section{Case 2}

A 40-year-old man consulted for a two week-history of sore throat, fever, and muscle aches, most notably on the legs. He received a course of amoxicillin-clavulanic acid, but his symptoms persisted. On consultation in our center, further interview showed that he had had three previous episodes of sore throat and fever in the past seven years that were accompanied by calf pains. The sore throat was associated with the occurrence of aphthous ulcers. As in Case 1, a review of systems showed no malar rashes, alopecia, history of epistaxis or chronic cough, joint pains, limb claudication, frothy urine, or hematuria. There were no tonsillar exudates; there were pustules on the left elbow, left leg, right ankle, and bilateral calf tenderness. There were no genital lesions, uveitis or visual disturbances, or any motor or sensory deficits. CBC showed mild leukocytosis. The antistreptolysin O (ASO) titer was $>200 \mathrm{IU} / \mathrm{ml}$, and urinalysis was normal. Antibiotics were continued. He reported oral ulcers lasting two weeks timed with the painful lesions in the legs on subsequent consults. BD (incomplete) was suspected. He was given methylprednisolone and colchicine.

There was an improvement on follow-up, with less pain and a shorter duration of oral ulcers. However, on one occasion, there was right leg pain aggravated by prolonged walking. There were red, $1.0-1.5 \mathrm{~cm}$ nodules on the right leg on physical examination, clinically assessed as erythema nodosum. Methotrexate and folic acid were added. Methotrexate was subsequently shifted to azathioprine when his alanine aminotransferase serum level became elevated. Subsequent clinic visits showed resolution of all symptoms, and steroids and azathioprine were tapered.

\section{Case 3}

A 32-year-old woman consulted at the clinic for leg pains. One year prior, she was admitted at a local hospital for bilateral leg pains, accompanied by fever, oral ulcers, and what was described as purpuric rashes that were nontender and non-pruritic on both legs. There was no history of visual disturbances, genital ulcers, or any motor and sensory deficits. Review of systems was unremarkable for malar rashes, alopecia, history of epistaxis or chronic cough, joint pains, limb claudication, frothy urine, or hematuria. There was also no history of obstetric complications. Her ESR and CRP were elevated at the time. She received prednisone which resolved the lesions and fever, but her symptoms would recur when prednisone was discontinued.

On the day of the consult at our center, she had bilateral leg pain and similar rashes of 4 days. ESR was $93 \mathrm{~mm} / \mathrm{hr}$ while $\mathrm{CBC}$ was normal. The ANA-IF was unremarkable. 
The rashes were clinically assessed to be vasculitic purpura. She was classified as having incomplete BD based on the presence of oral ulcers and purpuric rashes. She was given prednisone and colchicine, which resulted in a lesser recurrence of oral ulcers and the resolution of leg pains. Upon addition of methotrexate, oral ulcers resolved. Steroids are eventually tapered off, with plans to taper methotrexate on follow-up if symptoms are well controlled.

\section{Case 4}

A 54-year-old man consulted for the sudden onset of bilateral leg pain with no unusual activity as a precipitating event. The pain worsened after prolonged sitting during a 2-hour drive. On the same day, he developed a fever of 40 degrees Celsius, which lysed after intake of ibuprofen/ paracetamol. One day later, he noted a painful nodule on the left ankle's front, and his right wrist started becoming painful. Persistence of symptoms despite intake of oral ibuprofen/paracetamol prompted the consult. On review of systems, he reported a history of recurrent oral ulcers for the past 15 years, lasting about four days, approximately every six weeks. There was no history of malar rashes, alopecia, epistaxis or chronic cough, limb claudication, frothy urine, or hematuria. There was a tender nodule on the left anterior ankle on physical examination, a swollen, erythematous, and tender right wrist, and erythema on the ulnar side of the right $5^{\text {th }}$ finger. No oral or genital ulcers were noted at the time, and any visual disturbance or motor and sensory deficit. ASO titers were negative. ESR was elevated at 67 $\mathrm{mm} / \mathrm{hr}$. A diagnosis of incomplete BD was made based on recurrent ulcers and the presence of erythema nodosum-like lesions. He was given methylprednisone at $32 \mathrm{mg}$ per day, which was then tapered to $4 \mathrm{mg}$ per day upon improving symptoms. Steroids were eventually tapered off.

\section{DISCUSSION}

A summary of the clinical features, management, and outcome of the cases is presented in Table 1.

The 2013 International Criteria for BD (ICBD) proposes that a diagnosis of $\mathrm{BD}$ can be made when a patient scores 4 points based on the following criteria: ocular lesions, oral aphthosis, and genital aphthosis, which are assigned 2 points; and skin lesions, central nervous system involvement and vascular manifestations that are assigned 1 point each. The pathergy test, when used, was assigned 1 point. ${ }^{6}$ It remains a clinical diagnosis with no one pathognomonic sign, symptom, or laboratory test ${ }^{6,7}$. In some instances, patients are managed as incomplete $\mathrm{BD}$, where treatment is often initiated before the clinical criteria are fulfilled less the disease progressed irreversibly. ${ }^{8-10}$

In these four cases, a diagnosis of incomplete BD was made based on the following: the presence of skin lesions and oral ulcers, the suspicion of a vasculitic process underlying the leg pain and skin manifestations, and the absence of other systemic findings that would fulfill the classification criteria of another connective tissue disease or systemic vasculitis. In this case series, however, oral ulcers were not even among the main complaint and were discovered only on probing. Neither were genital ulcers, and ocular involvement was among the chief complaints. Simultaneously, only one out of the four only had pustular skin lesions-all signs and symptoms that are commonly the foremost manifestation of BD. ${ }^{2}$

Table 1. Characteristics, diagnosis, management, and outcomes of 4 patients presenting with leg pain

\begin{tabular}{|c|c|c|c|c|}
\hline & Case 1 & Case 2 & Case 3 & Case 4 \\
\hline Age, Gender, Race & 37-year-old female, Filipino & 40-year-old male, Filipino & 32-year-old female, Filipino & 54-year-old male, Filipino \\
\hline $\begin{array}{l}\text { Prior Diagnosis, } \\
\text { Management }\end{array}$ & $\begin{array}{l}\text { Systemic Lupus } \\
\text { Erythematosus, Prednisone }\end{array}$ & $\begin{array}{c}\text { Acute Pharyngitis with } \\
\text { Myalgia, Amoxicillin- } \\
\text { Clavulanic Acid }\end{array}$ & $\begin{array}{c}\text { Connective Tissue } \\
\text { Disease, Prednisone }\end{array}$ & $\begin{array}{l}\text { Behçet's Disease, } \\
\text { Methylprednisolone }\end{array}$ \\
\hline \multicolumn{5}{|l|}{ Symptoms } \\
\hline Oral aphthosis & + & + & + & + \\
\hline Skin lesions & + & + & + & + \\
\hline Vascular lesions & - & $\mathrm{nt}$ & $\mathrm{nt}$ & $\mathrm{nt}$ \\
\hline Pathergy test & - & $\mathrm{nt}$ & nt & $\mathrm{nt}$ \\
\hline Genital aphthosis & - & - & - & - \\
\hline Eye lesions & - & - & - & - \\
\hline $\begin{array}{l}\text { Time to Diagnosis } \\
\text { of BD (years) }\end{array}$ & 2 & 7 & 1 & 0.005 \\
\hline Management & $\begin{array}{l}\text { Colchicine } \\
\text { Prednisone }\end{array}$ & $\begin{array}{l}\text { Methylprednisolone } \\
\text { Colchicine } \\
\text { Folic Acid } \\
\end{array}$ & $\begin{array}{c}\text { Prednisone Azathioprine } \\
\text { Colchicine }\end{array}$ & Methylprednisolone \\
\hline Outcome & $\begin{array}{l}\text { No recurrence of leg pain, } \\
\text { oral ulcers, and skin lesions }\end{array}$ & $\begin{array}{l}\text { Recurrence of leg pain and } \\
\text { skin lesions and persistence } \\
\text { oral ulcer required the } \\
\text { addition of methotrexate }\end{array}$ & $\begin{array}{l}\text { No recurrence of leg pain; } \\
\text { Recurrence of oral ulcers } \\
\text { and skin lesions required the } \\
\text { addition of methotrexate }\end{array}$ & $\begin{array}{l}\text { No recurrence of leg pain, } \\
\text { skin lesions, and oral ulcers }\end{array}$ \\
\hline
\end{tabular}

nt - not tested 
These four cases instead had pain in the lower extremities as either the presenting or the prominent manifestation. In cases 1,2 , and 4 , the leg pain preceded the appearance of any tender skin lesions documented on physical examination, while in case 3, the leg pain was accompanied by nontender purpura. It is, therefore, difficult to establish whether the leg pain was simply a prodromal extension of a painful cutaneous lesion or an entirely different organ system affected by BD. In literature, calf pain in BD is attributed to arteritis, thrombophlebitis, and generalized myositis. ${ }^{3,8}$ In a case study by Haruki et al., vascular inflammation that caused arterial pseudoaneurysms and deep venous thrombosis was identified as the culprits for a 35-year-old man's leg pain and swelling, as seen on venous and arterial imaging studies. ${ }^{1}$ In another case study by Sarui et al., necrotizing myositis secondary to vasculitis was the cause of severe leg pain and weakness in a 29-year-old man, as seen in histopathologic studies. ${ }^{7}$

A complaint of leg pain should nevertheless prompt an inquiry or an examination of the skin overlying the affected leg. Erythema nodosum (EN), as part of the spectrum of skin involvement in $\mathrm{BD}$, comprises $38 \%$ - $99 \%$ of $\mathrm{BD}$ presentations, along with pustulosis and acneiform eruptions. ${ }^{6}$ It is a form of panniculitis characterized as a painful nodule located typically on the lower extremities' anterior sides. ${ }^{11}$ In itself, EN is a generally non-specific symptom of many inflammatory processes ranging from infections, infiltrative diseases like sarcoidosis and inflammatory bowel diseases. Recurrent EN in the background of elevated markers of inflammation may be the only manifestation of vasculitis. Leg pain accompanied by EN are clues to conditions like Takayasu Arteritis and BD. ${ }^{12}$ In this series, the history of erythema nodosum or pustular lesions though initially missed, was critical in arriving at the diagnosis.

Immunosuppressive agents such as steroids, methotrexate, and azathioprine control the underlying vasculitis in $\mathrm{BD}$, while colchicine is given for its effect on aphthous ulcers. ${ }^{2,8}$ The skin lesions and leg pain of all patients in this series responded promptly to steroids. However, colchicine was met with varying degrees of success: it prevented the recurrence of ulcers in 2 cases and decreased the frequency of recurrence in the rest. Two patients needed the addition of methotrexate and azathioprine to control their symptoms completely.

Notably, these cases were referred at least a year after their initial symptoms began. Though not typical of $\mathrm{BD}$, a chief complaint of leg pain should prompt the clinician to probe beyond common causes such as muscle strains or sprains, lumbosacral radiculopathies, or non-specific myalgia associated with systemic infections. The examination of skin over the affected limb could reveal skin lesions that may point to an inflammatory disease, which in turn may prompt a review of systems that includes often-overlooked signs and symptoms like those of oral and genital ulcers, skin lesions on other body parts, and eye pain or visual disturbances. A connective tissue disease or systemic vasculitis must then be considered, and vascular imaging or histopathologic studies of the affected leg must be pursued. In this context, a simple complaint of leg pain may lead to the diagnosis of a possibly destructive, if rare, disease like $\mathrm{BD}$. This thought process was demonstrated in this case series, where a complaint of leg pain led to the diagnosis of possible $\mathrm{BD}$, and experience in the first three cases led to the prompt diagnosis of the last one.

\section{Statement of Authorship}

All authors participated in the data collection and analysis, and approved the final version submitted.

\section{Author Disclosure}

All authors declared no conflicts of interest.

\section{Funding Source}

This paper was independently funded by the author.

\section{REFERENCES}

1. Haruki T, Miyasaka S, Maeta H, Morimoto K, Taniguchi I. VasculoBehçet's disease that began with femoral arterial report of a case. Annals of Vascular diseases. 2009;2(2):118-121. doi:10.3400/avd. AVDcr08015

2. Zeidan MJ, Saadoun D, Garrido M, Klatzmann D, Six A, Cacoub P. Behçet's disease physiopathology: a contemporary review. Autoimmunity Highlights. 2016;7(1):1-12. doi:10.1007/s13317-0160074-1

3. Conway R, Bergin D, Carey JJ, Coughlan RJ. A case of Behçet's syndrome presenting as focal myositis. Rheumatology (United Kingdom). 2012;51(6):975. doi:10.1093/rheumatology/ker450

4. Ng F, Chiong FJK, Buchanan R, Burrell LM. A rare case of Behçet disease with generalised myositis, cardiomyositis and necrotising fasciitis. BMJ Case Reports. 2016;2016:1-5. doi:10.1136/bcr-2015211983

5. Limgenco-Hipe J, Salido E, Penserga E. Disease characteristics of Behçet's disease among Filipino patients seen in rheumatology clinics. Philippine Journal of Internal Medicine. 2017;55(4).

6. Davatchi F, Assaad-Khalil S, Calamia KT, et al. The International Criteria for Behçet's Disease (ICBD): A collaborative study of 27 countries on the sensitivity and specificity of the new criteria. J Eur Acad Dermatol Venereol. 2014 Mar;28(3):338-47. doi: 10.1111/ jdv.12107. Epub 2013 Feb 26.

7. Sarui H, Maruyama T, Ito I, Takeda N, Nose M, Yasuda K. Necrotising myositis in Behçet's disease: characteristic features on magnetic resonance imaging and a review of the literature. Ann Rheum Dis. 2002 Aug;61(8):751-2. doi: 10.1136/ard.61.8.751.

8. Chikazawa S, Hanafusa T, Ozaki K, Namiki T, Amano M, Ueno M, et al. Incomplete Behçet's disease with calf muscle pain and MRI hyperintensity due to possible thrombophlebitis. Eur J Dermatol. 2017 Feb 1;27(1):76-7. doi: 10.1684/ejd.2016.2892.

9. Caporuscio S, Pranteda G, Nisticò S, Maucione T, Canzoni M, Stefani A, et al. An incomplete form of childhood Behçet's disease treated with infliximab. Int J Immunopathol Pharmacol. Jul-Sep 2014;27(3):445-8.

10. Akoğlu T, Paydaş S, Sarpel S, Tunali N, Tuncer I. Incomplete Behçet's syndrome with unusual manifestations. Annals of the Rheumatic Diseases. 1987;46(8):632-633. doi:10.1136/ard.46.8.632

11. Starba A, Chowaniec M, Wiland P. Erythema nodosum - Presentation of three cases. Reumatologia. 2016;54(2):83-5. doi:10.5114/reum. 2016.60218

12. Chowaniec M, Starba A, Wiland P. Erythema nodosum - Review of the literature. Reumatologia. 2016;54(2):79-82. doi:10.5114/reum. 2016.60217 